\title{
Aplikasi Monitoring Penderita Kardiovaskular dan Obesitas Berbasis Mobile Internet of Things (MIoT)
}

\author{
${ }^{1}$ Muhamad Bahrul Ulum, ${ }^{2}$ Nizirwan Anwar, ${ }^{3}$ Riya Widayanti, ${ }^{4}$ Alivia Yulfitri \& ${ }^{5}$ Hendra
}

\author{
1,2,5 Program Studi Teknik Informatika, Universitas Esa Unggul \\ ${ }^{3,4}$ Program Studi Sistem Informasi, Universitas Esa Unggul \\ Jl. Arjuna Utara No.9, Duri Kepa, Kec. Kebon Jeruk Kota Jakarta Barat 11510 \\ m.bahrul_ulum@esaunggul.ac.id
}

\begin{abstract}
According to the World Health Organization (WHO), coronary heart disease is the biggest cause of death in Indonesia. In 2016, the death rate from heart disease was 122 people per 100,000 population. This figure is higher than other causes, such as stroke, tuberculosis, and diabetes. The number is increasing every year due to changes in lifestyle of Indonesian people who like to eat high-fat foods and lifestyle factors that affect the risk of cardiovascular disease, including lack of physical activity, smoking, unhealthy diet, and alcohol consumption habits. This study aims to monitor the heart rate of cardiovascular sufferers with the mobile internet of things (MIoT) approach. Using the ESP8266 Wifi module for communication to the database server and heart rate sensor to detect heart rate then convert it to Bit per Minute (BPM). Every patient with cardiovascular disease can be monitored using a sensor connected to a smartphone to record any changes that occur. The research method consists of several stages, namely: Prepare, Plan, Design, Implement, Operate and Optimize (PPDIOO). The results obtained in the form of a aplication heart rate monitoring for patients with cardiovascular for healthcare services.
\end{abstract}

Keywords: . cardiovascular; heart rate; mobile internet of things

\section{PENDAHULUAN}

Indonesia merupakan negara kepulauan sehingga memberikan kendala tersendiri dalam usaha penanganan kesehatan, terutama kesehatan bagi penderita penyakit kardiovaskular. Penyakit kardiovaskular merupakan salah satu penyebab kematian tertinggi di Indonesia. Menurut Badan Kesehatan Dunia (WHO), penyakit jantung koroner merupakan penyebab kematian terbesar di Indonesia. Pada tahun 2016 angka kematian akibat penyakit jantung adalah 122 orang per 100.000 penduduk. Angka ini lebih tinggi dibanding penyebab lainnya seperti stroke, tuberkulosis dan diabetes. Jumlah tersebut meningkat setiap tahun karena perubahan gaya hidup masyarakat Indonesia yang suka makan makanan yang berlemak tinggi serta faktor gaya hidup yang mempengaruhi risiko penyakit kardiovaskular, antara lain kurangnya aktivitas fisik, merokok, pola makan tidak sehat dan kebiasaan konsumsi alkohol.

Telemedicine merupakan bidang ilmu yang memanfaatkan teknologi dalam bidang teknik elektro dan komputer untuk pelayanan kesehatan jarak jauh. Salah satu aplikasi dalam bidang telemedika adalah Telemonitoring berbasis mobile internet of things (MIoT). Internet of Things (IoT) adalah paradigma teknologi baru yang telah diadopsi di banyak bidang seperti kota pintar, organisasi kesehatan pintar, dan rumah pintar. Melihat tingkat kematian pasien penderita penyakit kardiovaskular yang relatif tinggi, maka diperlukan aplikasi monitoring bagi pasien penderita penyakit kardiovaskular.

Penelitian terkait dalam Sistem Monitoring Detak Jantung Bagi Penderita Kardiovaskular [1][2], Sistem monitoring penyakit jantung untuk layanan perawatan kesehatan [3], Sistem pemantauan pasien berbasis IoT [4], Prototipe sistem monitoring kondisi kesehatan pasien berbasis web [5], serta pemantauan Sistem pemantauan glukosa berkelanjutan berbasis IoT [6]. Tetapi penelitian tersebut belum mengkaji tentang aspek penerapan mobile internet of things (MIoT) untuk monitoring detak jantung pada penderita kardiovaskular.

Pada penelitian ini bertujuan untuk menerapkan mobile internet of things (MIoT) untuk memonitoring detak jantung penderita penyakit kardiovaskular. Setiap pasien penderita radiovaskular bisa dimonitor 
menggunakan sensor yang terhubung dengan smartphone untuk mencatat setiap perubahan detak jantung yang terjadi.

Urgensi penelitiannya yaitu melihat banyaknya penderita penyakit kardiovaskular, hal ini terutama bagi penderita di pedesaan yang jauh dari jangkauan dokter maka adanya monitoring penderita kardiovaskular berbasis MIoT ini akan membantu dalam penanggulangan penyakit kardiovaskular yaitu dengan cara pencatatan detak jantung dalam sistem monitoring yang terkoneksi pada database secara cepat dan tepat untuk menentukan langkah-langkah secara efektif sehingga setiap kondisi pasien dapat dipantau secara langsung (online) dan waktu-nyata (real-time).

\section{METODOLOGI PENELITIAN}

Metode yang digunakan dalam penelitian ini merupakan metodologi pendekatan dari Cisco system. Metode ini terdiri dari beberapa tahap, yaitu : Prepare, Plan, Design, Implement, Operate dan Optimize (PPDIOO). Berikut tahap-tahap PPDIOO Pada gambar 1.

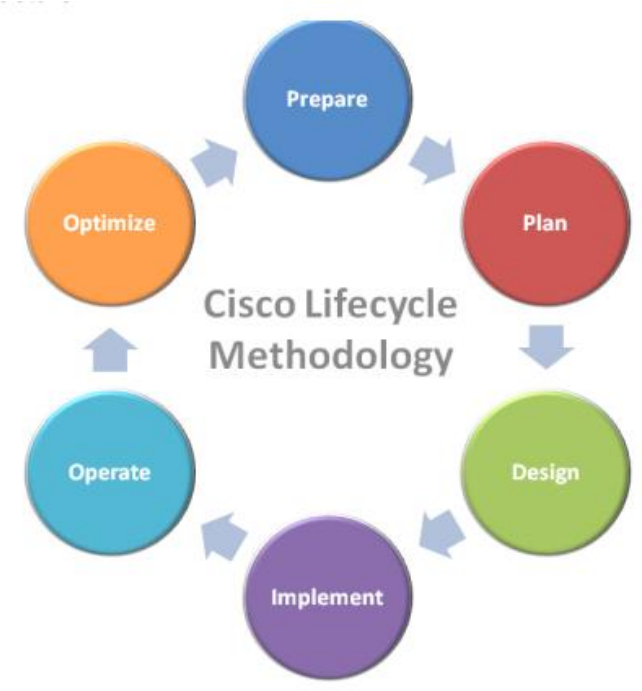

Gambar 1. Metode PPDIOO [7]

\section{Prepare}

Tahap ini diawali dengan menganalisa sistem monitoring penderita kardiovaskular dengan cara melakukan pengumpulan data dilakukan dengan survey lapangan ke RS yang ditujukan untuk memperoleh data primer dan memverifikasi model. Survey dilakukan dengan observasi dan wawancara yang terkait dengan penelitian ini.

\section{Plan}

Tahap ini diawali dengan mengidentifikasi kebutuhan dan dilakukan pengumpulan data dari berbagai pihak yang terkait dalam memonitoring penderita penyakit kardiovaskular dan obesitas.

\section{Design}

Kebutuhan awal yang telah ditentukan pada tahap Plan membentuk kegiatan desain arsitektur MIoT diimplementasikan pada dunia kesehatan untuk memonitoring penderita kardiovaskular.

\section{Implement}

Pada tahap ini adalah tahap implementasi dan verifikasi dimulai setelah desain telah disetujui. Jaringan dan komponen sistem tambahan yang dibangun sesuai dengan spesifikasi desain.

\section{Operate}


(C2020 Ilmu Komputer Unila Publishing Network all rights reserved

\section{Jurnal Komputasi}

pengujian akhir dari kesesuaian desain. Pada tahap ini dilakukan pemeliharaan sistem melalui pemantauan sehari-hari, yang mungkin termasuk memelihara ketersediaan dan mengurangi biaya.

\section{Optimize}

Tahap optimize tujuannya adalah untuk mengidentifikasi dan memecahkan masalah sebelum masalah nyata timbul.

\section{HASIL DAN PEMBAHASAN}

Untuk mengetahui kondisi atau keadaan tubuh pada manusia, bisa diketahui dengan mengukur detak jantung. Pengukuran detak jantung mengacu pada 3 kriteria yaitu jenis kelamin, usia dan aktifitas. Dapat dilihat pada Tabel 1, Tabel 2, dan Tabel 3.

Tabel 1. Detak Jantung Istirahat Laki-Laki [8]

\begin{tabular}{lcccccc}
\hline \multirow{2}{*}{\multicolumn{1}{c}{ Kondisi }} & \multicolumn{6}{c}{ USIA } \\
\cline { 2 - 7 } & $18-25$ & $26-35$ & $36-45$ & $46-55$ & $56-65$ & $65+$ \\
\cline { 2 - 7 } & & \multicolumn{5}{c}{ Detak Jantung (BPM) } \\
\hline Sangat Baik Sekali & $49-55$ & $49-54$ & $50-56$ & $50-57$ & $51-56$ & $50-55$ \\
\hline Sangat Baik & $56-61$ & $55-61$ & $57-62$ & $58-63$ & $57-61$ & $56-61$ \\
\hline Baik & $62-65$ & $62-65$ & $63-66$ & $64-67$ & $62-67$ & $62-65$ \\
\hline Lebih dari Cukup & $66-69$ & $66-70$ & $67-70$ & $68-71$ & $68-71$ & $66-69$ \\
\hline Cukup & $70-73$ & $71-74$ & $71-75$ & $72-76$ & $72-75$ & $70-73$ \\
\hline Kurang & $74-81$ & $75-81$ & $76-82$ & $77-83$ & $76-81$ & $74-79$ \\
\hline Buruk & $82+$ & $82+$ & $83+$ & $84+$ & $82+$ & $80+$ \\
\hline
\end{tabular}

Tabel 2. Detak Jantung Istirahat Perempuan [8]

\begin{tabular}{lcccccc}
\hline \multirow{2}{*}{ Kondisi } & \multicolumn{6}{c}{ USIA } \\
\cline { 2 - 7 } & $18-25$ & $26-35$ & $36-45$ & $46-55$ & $56-65$ & $65+$ \\
\cline { 2 - 7 } & & \multicolumn{5}{c}{ Detak Jantung (BPM) } \\
\hline Sangat Baik Sekali & $54-60$ & $54-59$ & $54-59$ & $54-60$ & $54-59$ & $54-59$ \\
\hline Sangat Baik & $61-65$ & $60-64$ & $60-64$ & $61-65$ & $60-64$ & $60-64$ \\
\hline Baik & $66-69$ & $65-68$ & $65-69$ & $66-69$ & $65-68$ & $65-68$ \\
\hline Lebih dari Cukup & $70-73$ & $69-72$ & $70-73$ & $70-73$ & $69-73$ & $69-72$ \\
\hline Cukup & $74-78$ & $73-76$ & $74-78$ & $74-77$ & $74-77$ & $73-76$ \\
\hline Kurang & $79-84$ & $77-82$ & $79-84$ & $78-83$ & $78-83$ & $77-84$ \\
\hline Buruk & $85+$ & $83+$ & $85+$ & $84+$ & $84+$ & $84+$ \\
\hline
\end{tabular}

Tabel 3. Detak Jantung Maksimum dan Target [9]

\begin{tabular}{ccc}
\hline Usia (Tahun) & Target Detak Jantung (50-85\%) & Rata-rata Maksimum Detak Jantung (100\%) \\
\hline $\mathbf{2 0}$ & $100-170$ beats per minute $(\mathrm{bpm})$ & $200 \mathrm{bpm}$ \\
\hline $\mathbf{3 0}$ & $95-162 \mathrm{bpm}$ & $190 \mathrm{bpm}$ \\
\hline $\mathbf{3 5}$ & $93-157 \mathrm{bpm}$ & $185 \mathrm{bpm}$ \\
\hline $\mathbf{4 0}$ & $90-153 \mathrm{bpm}$ & $180 \mathrm{bpm}$ \\
\hline $\mathbf{4 5}$ & $88-149 \mathrm{bpm}$ & $175 \mathrm{bpm}$ \\
\hline $\mathbf{5 0}$ & $85-145 \mathrm{bpm}$ & $170 \mathrm{bpm}$ \\
\hline $\mathbf{5 5}$ & $83-140 \mathrm{bpm}$ & $165 \mathrm{bpm}$ \\
\hline $\mathbf{6 0}$ & $80-136 \mathrm{bpm}$ & $160 \mathrm{bpm}$ \\
\hline $\mathbf{6 5}$ & $78-132 \mathrm{bpm}$ & $155 \mathrm{bpm}$ \\
\hline
\end{tabular}




\subsection{Arsitektur Sistem}

Arsitektur umum aplikasi IoT dapat dibagi menjadi tiga lapisan: lapisan penginderaan, lapisan transport dan lapisan aplikasi. Gambar 2 menunjukkan Desain Arsitektur Sistem Aplikasi Monitoring Penderita Kardiovaskular dan Obesitas.

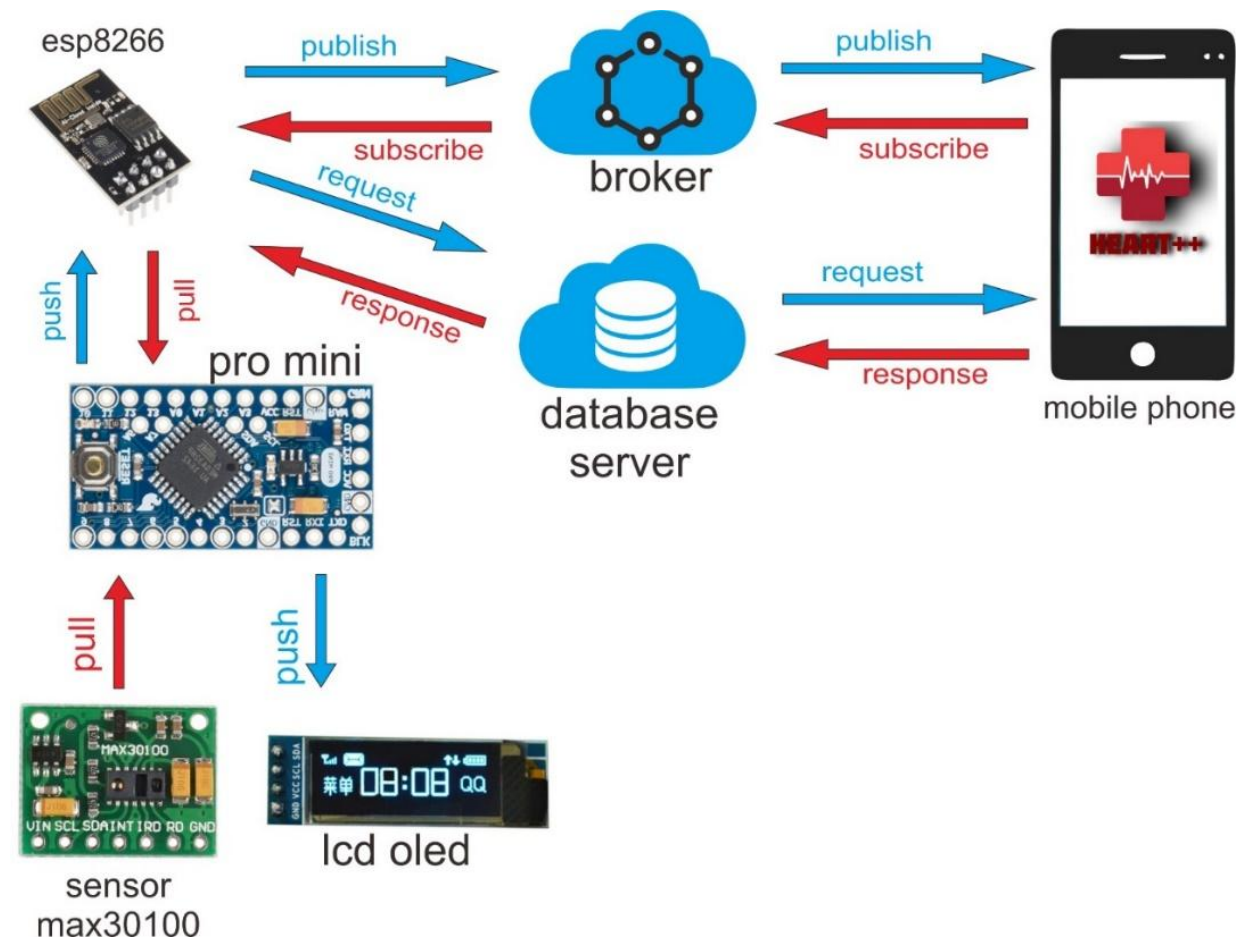

Gambar 2. Arsitektur Sistem Aplikasi Monitoring Penderita Kardiovaskular dan Obesitas

\subsection{Desain Sistem}

Pada sistem monitoring ini menggunakan mcu pro mini 5v sebagai komponen untuk mengolah data. Modul Wifi ESP8266 untuk komunikasi ke database server dan sensor heart rate Max 301000 untuk mendeteksi detak jantung yang kemudian dikonversi ke Bit per Minute (BPM). Hasil pembacaan data akan di tampilkan pada lcd oled 1306, dapat dilihat pada gambar 3.

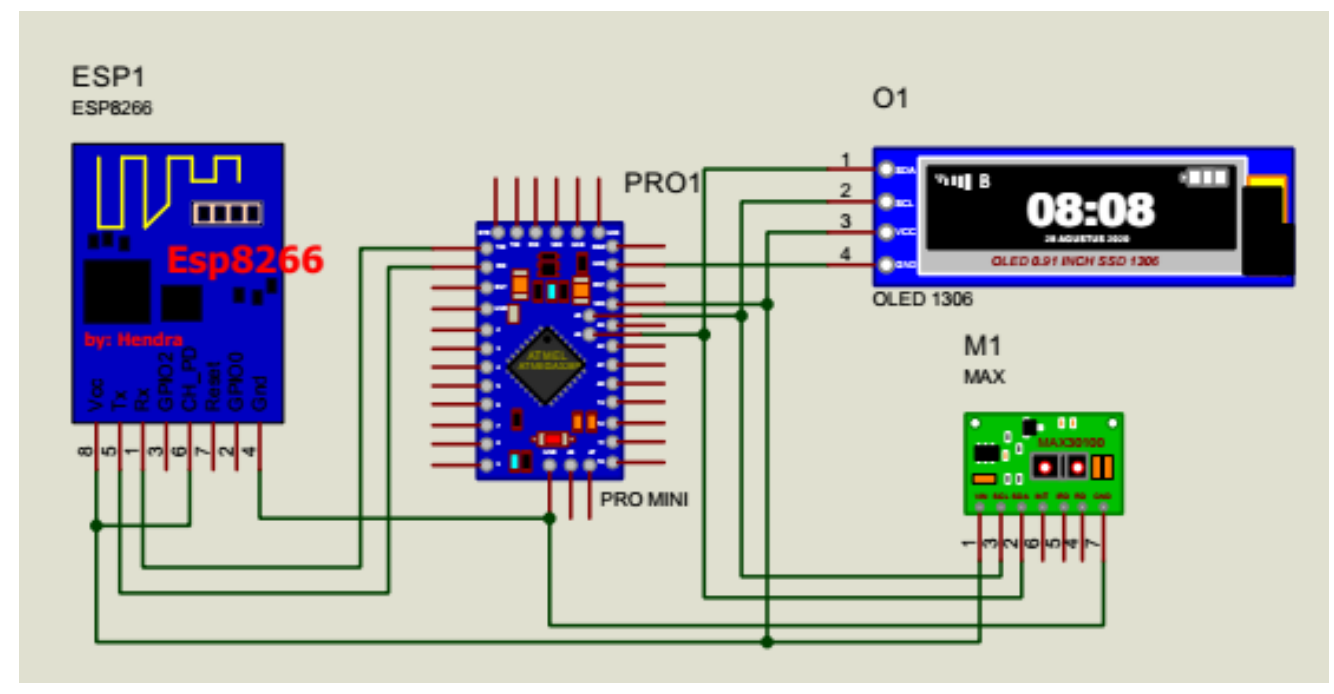

Gambar 3. Desain Sistem Aplikasi Monitoring Penderita Kardiovaskular dan Obesitas 


\subsection{Cara Kerja Aplikasi}

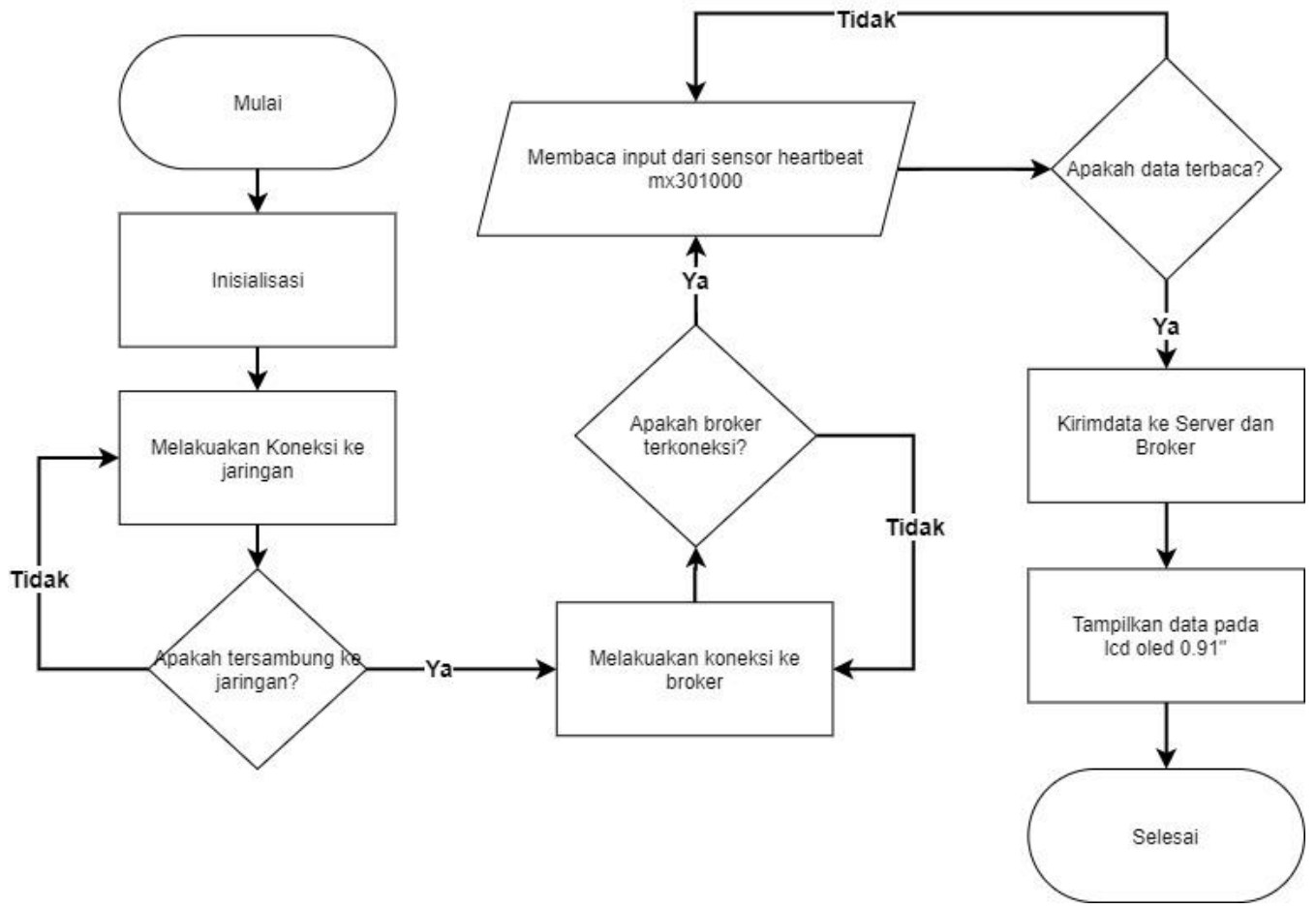

Gambar 4. Cara Kerja Aplikasi

Dari gambar 4 di atas, Cara kerja aplikasi penderita kardiovaskular dan obesitas dimulai dengan inisialisasi sensor yang ada pada board, kemudian melakukan koneksi ke jaringan yang telah di sediakan, kemudian melakukan koneksi ke broker melalui jaringan yang telah tersambung, jika jaringan dan broker telah terkoneksi dengan benar kemudian pembacaan sensor dilakukan jika pembacaan terdapat nilai lebih besar dari 0 maka hardware akan melakukan publish ke broker kemudian menyimpan data detak jantung disimpan pada database server, Hasil pembacaan data akan di tampilkan pada lcd oled. 
Vol. 8 No. 2, 2020

(C2020 Ilmu Komputer Unila Publishing Network all rights reserved

\subsection{Implementasi Sistem}

\subsubsection{Tampilan Awal Aplikasi}

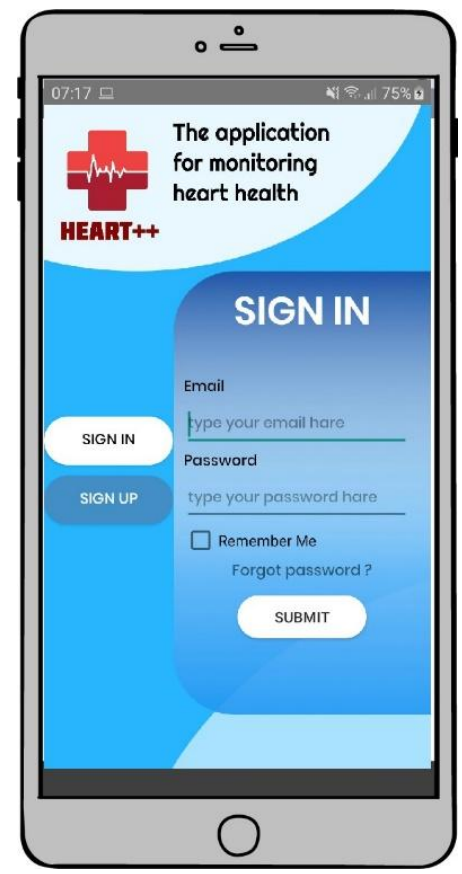

Gambar 5. Halaman Login

Pada Gambar 5, Menu halaman ini user diminta untuk mendaftar terlebih dahulu sebelum bisa masuk ke dalam aplikasi monitoring.

\subsubsection{Tampilan Input Data Pasien}

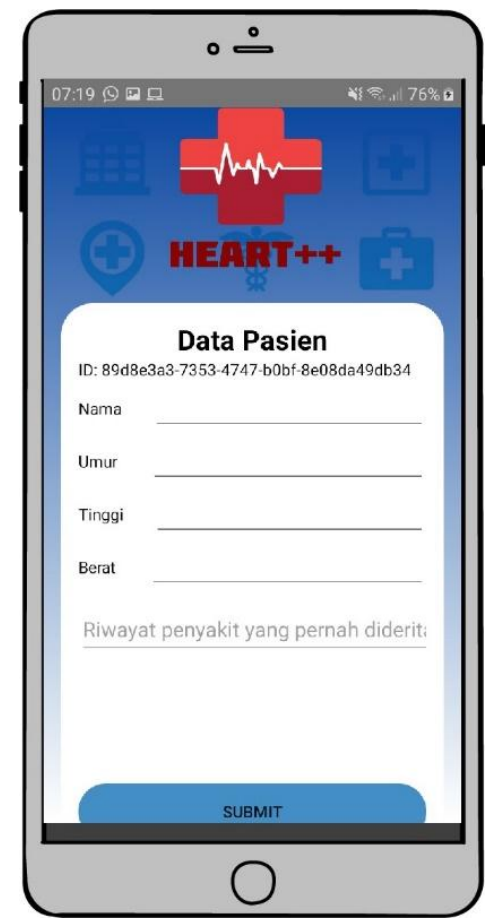

Gambar 6. Halaman Input Data Pasien 
Pada Gambar 6, setelah user login untuk masuk ke aplikasi, kemudian user diminta untuk menginput data pasien dan riwayat penyakit yang pernah diderita, sehingga data pasien bisa di simpan dalam database server.

\subsubsection{Tampilan Hasil Monitoring}

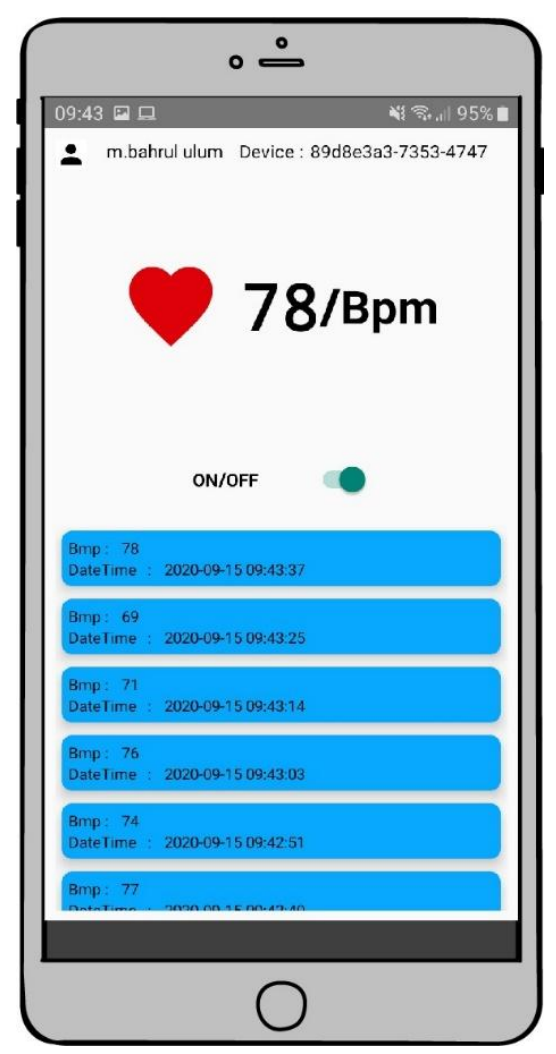

Gambar 7. Tampilan Hasil Monitoring Detak Jantung

Pada gambar 7. Aplikasi monitoring kesehatan yang terintegrasi sehingga dapat memperoleh, merekam dan menampilkan data dari detak jantung pasien setiap saat. Sistem monitoring berbasis MIoT yang akan memberikan output berupa grafik dari hasil detak jantung manusia melalui aplikasi.

\section{KESIMPULAN}

Berdasarkan hasil penelitian didapat berupa aplikasi monitoring detak jantung bagi penderita kardiovaskular. Nilai detak jantung bisa ditampilkan pada layar aplikasi secara realtime, hal ini terutama bagi penderita di pedesaan yang jauh dari jangkauan dokter maka adanya monitoring detak jantung bagi penderita kardiovaskular berbasis MIoT ini akan membantu dalam penanggulangan penyakit kardiovaskular yaitu dengan cara pencatatan detak jantung dalam sistem monitoring yang terkoneksi pada database server secara cepat dan tepat untuk menentukan langkah-langkah yang efektif sehingga setiap kondisi pasien dapat monitor secara langsung dan realtime.

\section{DAFTAR PUSTAKA}

[1] M. B. Ulum and M. Tarigan, "Perancangan Sistem Monitoring Detak Jantung Bagi Penderita Kardiovaskular Berbasis Internet of Things," J. Komputasi, vol. 8, no. 1, pp. 15-20, 2020, doi: 10.23960/komputasi.v8i1.2419.

[2] R. Adil, "PERANCANGAN SISTEM MONITORING ONLINE PADA PASIEN PENDERITA JANTUNG KORONER," pp. 181-186, 1986.

[3] Z. Li, Chao; Hu, Xiangpei ; Lili, "The IoT-based heart disease monitoring system for pervasive 
(C2020 Ilmu Komputer Unila Publishing Network all rights reserved

\section{Jurnal Komputasi} healthcare service.pdf." pp. 2328-2334, 2017.

[4] J. Gómez and B. Oviedo, "Patient Monitoring System Based on Internet of Things," Procedia Procedia Comput. Sci., vol. 83, no. June, pp. 90-97, 2016, doi: 10.1016/j.procs.2016.04.103.

[5] S. Mulyono, "Rancang Bangun Prototipe Sistem Pemantau Kondisi Kesehatan Pasien Berbasis Web," vol. 2, no. 2, pp. 250-259, 2013.

[6] T. N. Gia, M. Ali, I. Ben Dhaou, A. M. Rahmani, T. Westerlund, and P. Liljeberg, "An IoT-based continuous glucose monitoring system : A feasibility study IoT-based continuous glucose monitoring system : A feasibility study,” no. May, 2017, doi: 10.1016/j.procs.2017.05.359.

[7] C. Systems, "CREATING BUSINESS VALUE AND OPERATIONAL EXCELLENCE," pp. 1-10, 2010.

[8] TopendSport, "Resting Heart Rate Table," 2019. www.topendsports.com/testing/heart-rate-restingchart.htm.

[9] American Heart Association, "Target Heart Rate," 2019. www.heart.org/en/healthyliving/fitness/fitness-basics/target-heart-rates. 